\title{
Effect of Beryl Addition on Mechanical Properties of A17075 Using a Stir Casting Technique
}

\author{
Shanawaz Patil, Mohamed Haneef
}

\begin{abstract}
In present study, Al7075-Beryl synthesized by using a stir casting technique. The different weight percentage of Beryl incorporated are $2 \mathrm{Wt} . \%$ to $8 \mathrm{Wt} . \%$ in steps of $2 \mathrm{Wt} . \%$. The effect of Beryl particles integration on hardness and tensile strength response on Al7075 were investigated. It is demonstrated that Beryl particles distributed homogeneously in the Al7075 matrix acts as effective reinforcement to enhance the mechanical properites. Compared to base Al7075 matrix, Al7075- 6 wt.\% Beryl composites exhibited higher yield strength of $47.42 \%$, ultimate tensile strength of $44.08 \%$ and Al7075-8Wt.\% enhancement in hardness of $27.71 \%$ when compared to momlithic Al7075. As cast Al7075 alloy and Al7075-Beryl composites were microstructurally characterized with scanning electron microscopy (SEM), Energy dispersive spectrum (EDS) and X-ray diffraction (XRD). Microstructure study through scanning electron microscope study reveals that the uniform distribution reinforcement Beryl into Al7075 matrix. The Al7075Beryl.
\end{abstract}

\section{Keywords: Al7075, Beryl, Hardness, SEM, Tensile strength}

\section{INTRODUCTION}

Evolution in the filed of materials and technology has always lead to the development newer materials. Composite materials is a combination of two or more materials with non identical physical or chemical properties, when intermixed produces entirely unique product with enhanced properties. Metal matrix composites (MMCs) are the emerging materials owing to their improved properties. The usage of MMCs were increasing day by day because, they have high strength-weight ratio with other properties like high elastic modulus, hardness and wear resistance when compared to conventional monolithic materials. The MMCs are most widely used in the industires like aerospace, automotive, military goods, sports and recreational products. There are several materials available with different properties one of them being aluminum and its alloys[1-5]. Engineering applications required the materials with light weight and high strength which is provided by the aluminum metal matrix composites (AMMCs). Aluminum alloys and its composites has given tremendous mechanical, tribological, thermal and electrical properties. Several researcher has put their effort to find out the different peroperties of AMMCs. A17075 alloy is one of the vital material used in aerospace and structural applications owing to its high strength and corrosion resistance. Selection of reinforcement is most vital part in the development of aluminum composites[6-10]. Reza et al., reported that the incorporation of nano alumina partciles into Al6061 matrix led to improvement in yield strength and ultimate strength of Al6061-Nano alumina composites[11]. Rahman et al., reported tha the incorporation of varying weight percentage $(0,5,10, \& 20 \mathrm{Wt} . \%)$ of silicon carbide in aluminum matrix material synthesized by using stir casting process led to strengthen the alumina-SiC composites[12]. Yuan et al., reported that increase in weigth percentage of Boron content led to agglomeration and uneven distribution of boron in $\mathrm{Al}$ matrix and also coccluded that $\mathrm{Al}$ with $7 \mathrm{Wt}$ \% of Boron has given better yield and tensile strength of Al-Boron composites[13]. Various ceramical reinforcement such as Silicon Carbide having density $3.2 \mathrm{~g} / \mathrm{cc}$ and hardness 2600 $\mathrm{HV}$. Titanium carbide (TiC) having density of $4.93 \mathrm{~g} / \mathrm{cc}$ and hadrness of $2900 \mathrm{HV}$. Boron carbide (B4C) having density of $2.52 \mathrm{~g} / \mathrm{cc}$ and hardness of $2800 \mathrm{HV}$ [14-16]. Development of composites attains complications due to variations in densities of reinforcement andmatrix material. Hence it is an important parameter to select reinforcement which is almost same as matrix material. Beryl is one of the naturally available reinforcement having desisty ranging between $2600 \mathrm{~g} / \mathrm{cc}$ to $2800 \mathrm{~g} / \mathrm{cc}$ which is almost equal to aluminum density[17]. Suresh et al., study reported that addition of Beryl particles in to aluminum increases the hardness and tensile strength of Al-Beryl composites by $11 \%$ due to lack of decline porosity and fine grain refinement synthesized by stir casting and squeeze casting process[18]. Hosur Nanjireddy Reddappa et al. reported that the incorporation of Beryl particles into the Al6061 alloy significantly enhances the mechanical properties and reduces the wear of the Al6061-Beryl composites when compared to base Al6061 alloy. Al6061-10 Wt.\% of Beryl showed, 15.38\% of enhancement in tensile strength and also $8.9 \%$ of reducing in wear of Al6061- 10Wt.\% of Beryl when compared to Al6061 alloy[19].

The present research aims to reveal the mechanical properties of A17075-Beryl composites synthesized via liquid metallurgy process (stir casting). The developed Al7075 and Al7075-varying weight percentage of Beryl has ben subjected to hardness yield strength and tensile strength. The microstructure characterization of the composites was analyzed using SEM and XRD analysis.

Revised Manuscript Received on 14, October 2019.

Shanawaz Patil, Research Scholar, VTU Belagavi, Assistant Professor, School of Mechanical Engineering, REVA University, Bengaluru, Karnataka, India

Dr. Mohamed Haneef, Professor, Department of Mechanical Engineering, Ghousia College of Engineering, Ramanagar, India 


\section{EFFECT OF BERYL ADDITION ON MECHANICAL PROPERTIES OF AL7075 USING A STIR CASTING TECHNIQUE}

\section{EXPERIMENTAL PROCEDURES}

\subsection{Materials and Composite Synthesis}

In this research, matrix materials selected is Al7075 alloy, the alloying elements of Al7075 include zinc, magnesium, and copper leads to corrosion resistance, high strength, and hardness. Al7075 alloy has exceptional properties and found in many aerospace components. The composition and detailed elements weight percentage of selected Al7075 alloy is shown in Table 1.

Table 1. Composition of Al 7075 Matrix alloy

\begin{tabular}{|l|l|}
\hline Elements & Wt. \% \\
\hline Zinc & 5.602 \\
\hline Magnesium & 2.506 \\
\hline Copper & 1.598 \\
\hline Chromium & 0.253 \\
\hline Titanium & 0.18 \\
\hline Iron & 0.106 \\
\hline Silicon & 0.001 \\
\hline Manganese & 0.052 \\
\hline
\end{tabular}

\subsection{Reinforcing Materials:}

Beryl $(\mathrm{Be})$ is also acknowledged as Beryllium Aluminum Cyclosilicate. Its chemical formula is $\left(\mathrm{Be}_{3} \mathrm{Al}_{2}\left(\mathrm{SiO}_{3}\right)_{6}\right)$. The major elements Beryl contains are Silicon oxide (Wt.\% 62.12 ), Aluminum oxide (Wt.\% 18.05), Beryllium oxide (Wt.\% 8.24), Ferric Oxide $\left(\mathrm{Fe}_{2} \mathrm{O}_{3}\right)$ and Calcium oxide (Wt.\% 1.34). Beryl is a mineral, naturally occurs and very hard reinforcements. Beryl density is almost the same as aluminum of about 2600 to $2800 \mathrm{~kg} / \mathrm{m}^{3}$. The particle size of the Beryl used in the present study ranges between 30 to 50 microns.

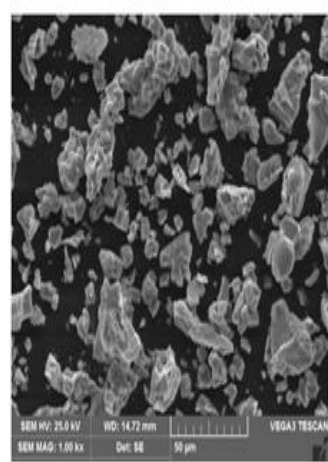

Figure 1. SEM micrograph of Beryl particles

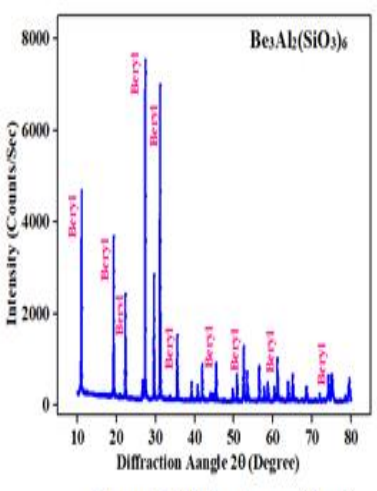

Figure 2. XRD pattems of Beryl
Figure. 1 represent the SEM image (scanning electron micrograph) of Beryl and Figure. 2 shows the XRD analysis of Beryl. The presence of Beryl and its hexagonal crystal structure was found in XRD analysis.

\subsection{Methods:}

Al7075 and Al7075-Beryl were synthesized by stir casting method. Stir casting, a most economical method for synthesis of A17075-Beryl composites was adopted. Firstly $2 \mathrm{~kg}$ of A17075 ingots kept in a graphite crucible and was melted at $800{ }^{\circ} \mathrm{C}$ by using an electric furnace. A mechanical stirrer was used to create a vortex in an Al7075 melt. The stirrer speed maintained was $300 \mathrm{rpm}$.Then preheated varying weight percentage of Beryl partices (2Wt.\%,
$4 \mathrm{Wt} . \%, 6 \mathrm{Wt} . \%$, and $8 \mathrm{Wt} . \%$ ) were added into the vortex of Al7075 metl. The melt is degassed by using a degassing tablet. Finally, the molten metal is poured into the preheated cast-iron molds. The cast samples are subjected to characterization. Table 3 shows the extent of the combination of Beryl in the Al 7075 alloy.

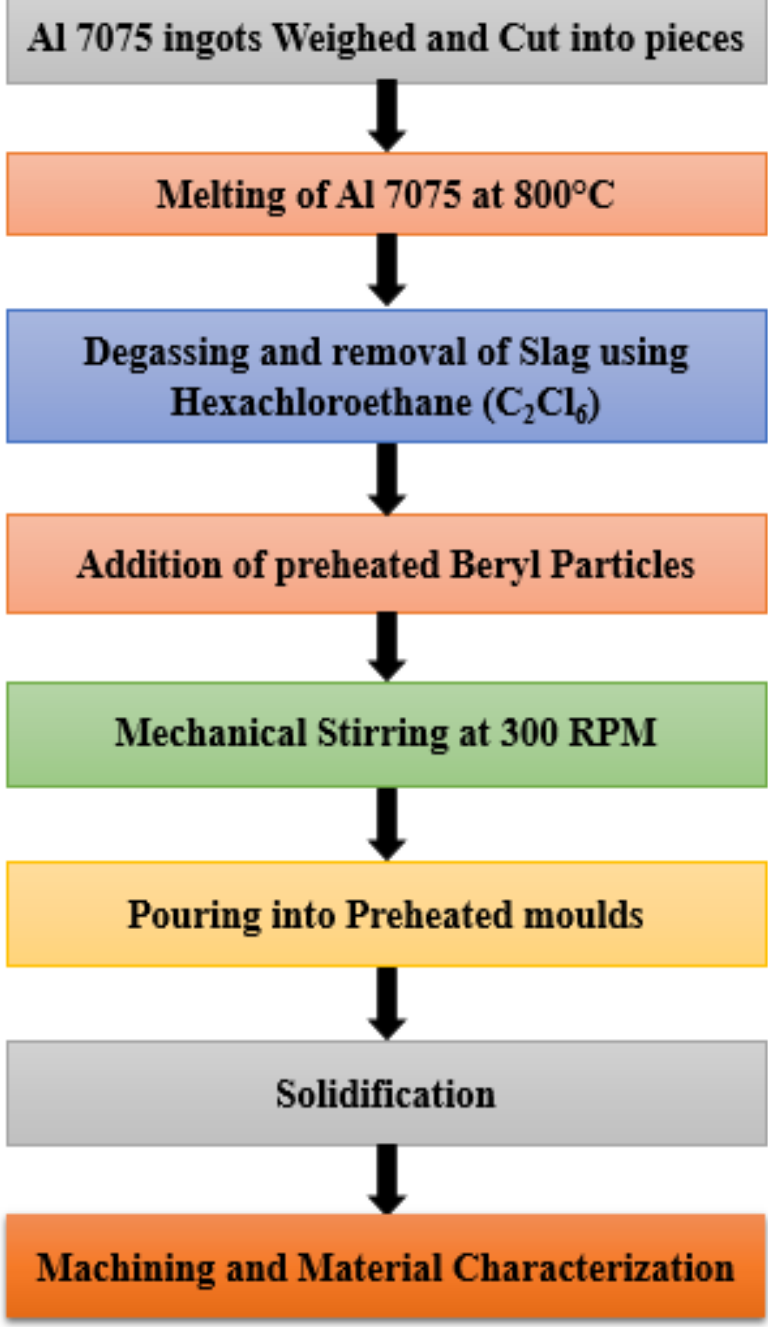

Figure 3: Flow diagram of Stir Casting Process for Al7075/Beryl Composite

Table 2. List of composites prepared

\begin{tabular}{|l|l|}
\hline Sample & Composites \\
\hline A & Al7075 \\
\hline B & Al7075 - 2 Wt.\%Beryl \\
\hline C & Al7075 - 4 Wt.\%Beryl \\
\hline D & Al7075 - 6 Wt.\%Beryl \\
\hline E & Al7075-8 Wt.\%Beryl \\
\hline
\end{tabular}

2.5 Characterizations of Al7075-Beryl Composites and Mechanical properties

Microstructural studies are essential in finding the grain size, grain shape and distribution of reinforcing particulates within the base matrix. The prepared A17075 and Al7075Beryl composites were subjected for machining, polishing and application of etchant before is is subjecting to microstrucutal studies. In this study Kellar's etchant 
$\left(\mathrm{HCL}+\mathrm{HF}+\mathrm{HNO}_{3}+\mathrm{H}_{2} \mathrm{O}\right)$ was used to amplify the microstructural view. microstructures were studied using a scanning electron microscope. The presence of Beryl and aluminum were analyzed using X-ray diffraction (XRD) method. The equipment used for XRD analysis was PANanlytical-X'Pert ${ }^{3}$ Powder. The surface analysis and tensile fracture surfaces of synthesized composites were carried out using a scanning electron microscope. The equipment for SEM analysis was Hitachi, (Model:SU $3500 \mathrm{~N}$ ), having resolutions of $7 \mathrm{~nm}$ SE Image at $3 \mathrm{kV}, 10$ $\mathrm{nm}$ BSE Image at $5 \mathrm{kV}$ equipped with energy dispersive spectroscopy (EDS). The mechanical properties such yield strength, tensile, and hardness test specimens. The tensile test was carried out on as-cast composites and matrix materials as per the ASTM-E8 standard. The hardness test was carried out as per ASTM E10.

\section{RESULTS AND DISCUSSION}

\subsection{Microstructural observations}

The microstructure of Al 7075 and hybrid A17075- Beryl are shown in Figure 4. The microstructure study clearly reveals that the clear surfaces with minimal porosity. The SEM micrographs investigation reveals that microstructure consists of uniform distribution of fine Beryl, and intermetallic compounds dispersed along the grain boundary in the matrix of $\mathrm{Al} 7075$ and there is good bonding between Beryl and Al7075 alloy. Uniform distribution and good bonding of Beryl within the Al 7075 enhances the properties[20].

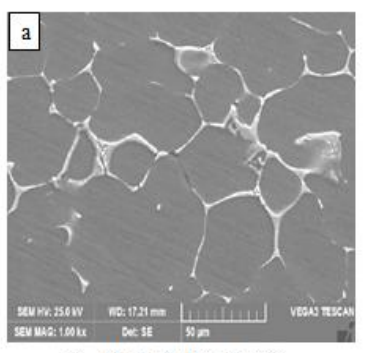

a) Al 7075 alloy matrix

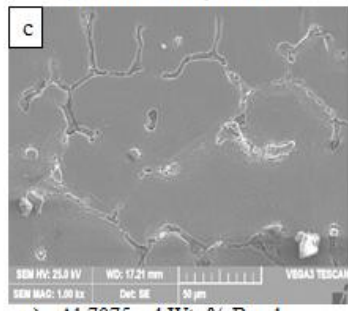

c) Al 7075 - 4 Wt. $\%$ Beryl

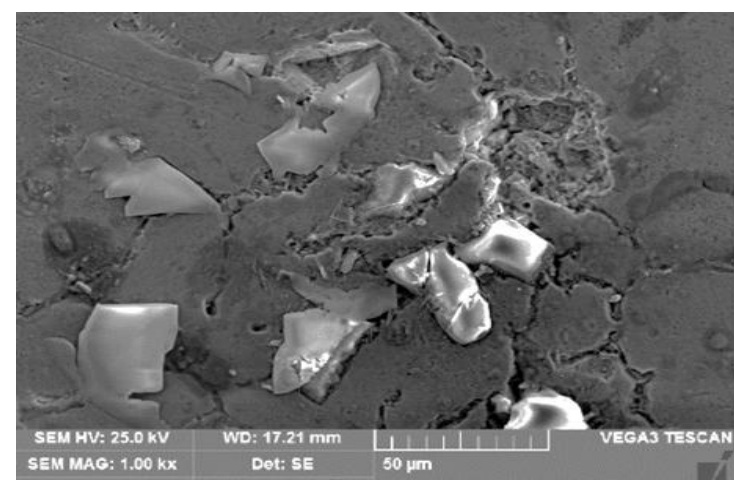

e) Al 7075 - $8 \mathrm{Wt}$ \% Beryl

Figure 4: SEM image of Al7075-Beryl Composites

\subsection{Energy Dispersive Spectroscopy (EDS)}

EDS analysis spectrum reveals that the presence of aluminum as the highest element followed by Beryl (Be), Zinc (Zn), Magnesium (Mg), Copper (Cu), and Silicon ( $\mathrm{Si})$, as other elements. Table 3 represents the spot EDS composition of $\mathrm{Al} 7075$ - Beryl composites in weight percentage. Figure 5 depits the EDS analysis plot for Al7075-Beryl compoistes

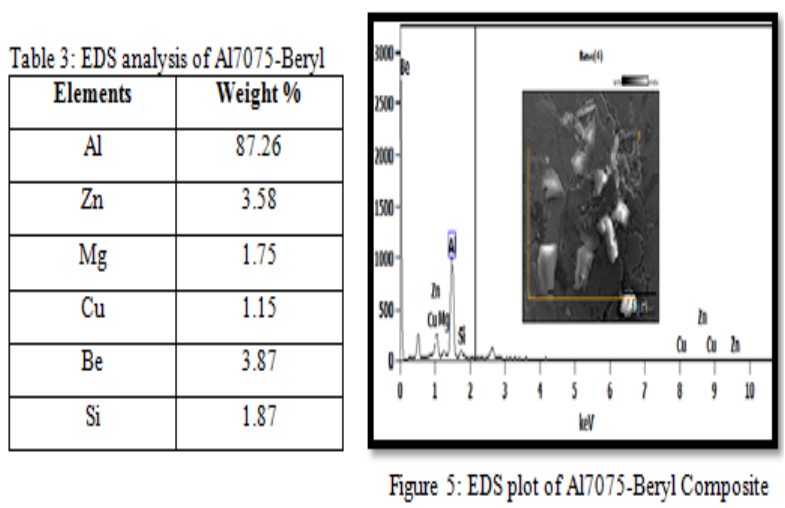

Figure 5: EDS plot of Al7075-Beryl Composite

\section{$3.3 X$-ray diffraction analysis}

Figure 6 shows X-ray diffraction patterns of as-cast Al7075 alloy and its composites reinforced with Beryl. The XRD analysis study reveals that the peaks height increases as weight percentage of Beryl increases. X-ray intensities of peak $38^{\circ}, 45^{\circ}, 65^{\circ}$ and $78^{\circ}$ indicating the presence of aluminum phase[20]. X-ray intensity for Beryl particles indicates at $11.6^{\circ}, 27.3^{\circ}$ and $31.12^{\circ}(2 \theta$-angle).

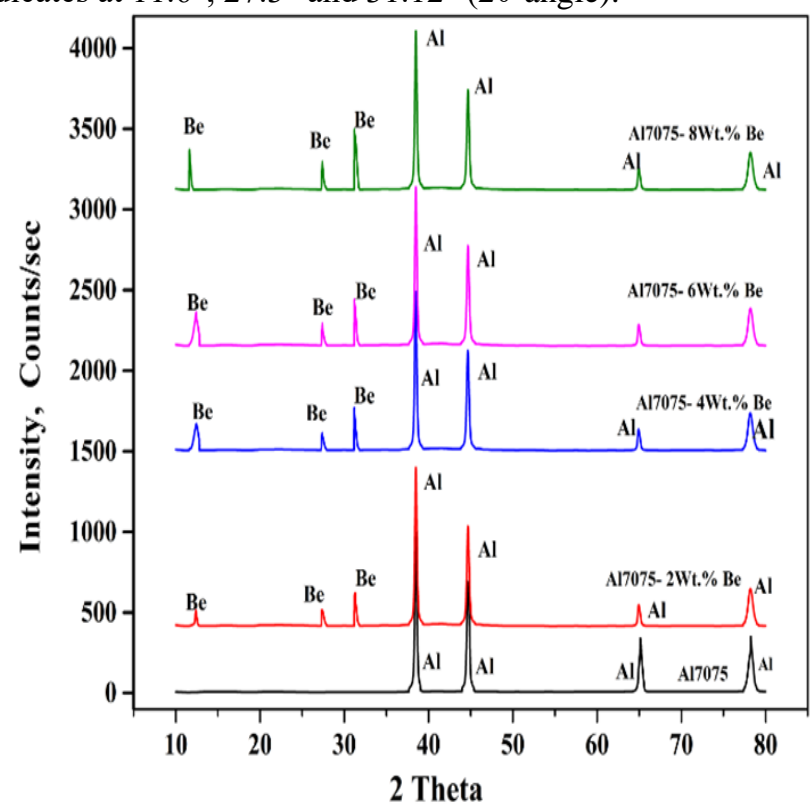

Figure 6: XRD patterns of as-cast Al7075 alloy and its composites

\subsection{Tensile Strength:}

The results of the ultimate tensile test of Al7075 \& Al7075-Beryl cast specimens are tabulated in Table 4. 
TECHNIQUE

Table 4. Tensile strength results

\begin{tabular}{|l|l|l|}
\hline Sample & $\begin{array}{l}\text { Sample } \\
\text { Designation }\end{array}$ & $\begin{array}{l}\text { Ultimate Tensile } \\
\text { Strength (MPa) }\end{array}$ \\
\hline A & Al7075 & 139.187 \\
\hline B & Al7075 + 2wt.\% & 151.628 \\
\hline C & Al7075 + 4wt.\% & 167.524 \\
\hline D & Al7075 + 6wt.\% & 188.433 \\
\hline E & Al7075 + 8wt.\% & 180.229 \\
\hline
\end{tabular}

The relationship between the UTS of the developed composites with different weight fractions of Beryl particles is shown in Figure 7.

The tensile strength of the A17075 alloy and Al7075Beryl were determined by using UTM. It is inferred from the test results that, the tensile strength of hybrid MMC increases with an increasing percentage of reinforcement and maximum tensile strength is achieved for $6 \mathrm{Wt} . \%$ of Beryl. This is because the Beryl particles act as obstacles to the dislocations related to thermal expansion divergence between A17075 alloy and Beryl when the external load applied. The coefficient thermal expansion (CTE) for Al7075 alloy is $22.2 \times 10^{-6} \mathrm{~K}^{-1}$, for Beryl $2.6 \times 10^{-6} \mathrm{~K}^{-1}$. In addition, the elastic modulus of Al7075 alloy is $71 \mathrm{GPa}$, Beryl $287 \mathrm{GPa}$. Thus, great differences between CTE and elastic modulus of matrix material and reinforcement lead to formation of dislocations at the interface. These dislocations at the interface will resist the external load and thereby leads to resisting the fracture[20-24]. This resistance fracture leads to increase in tensile strength The tensile strength for Al7075-6 Wt.\% Beryl showed enhancement of $\mathbf{3 5 . 3 8 \%}$ as compared matrix material. Further incorporation of hard Beryl particles into soft matrix leads to increased strength. Similar observation reported by Suresh et al.,[18]

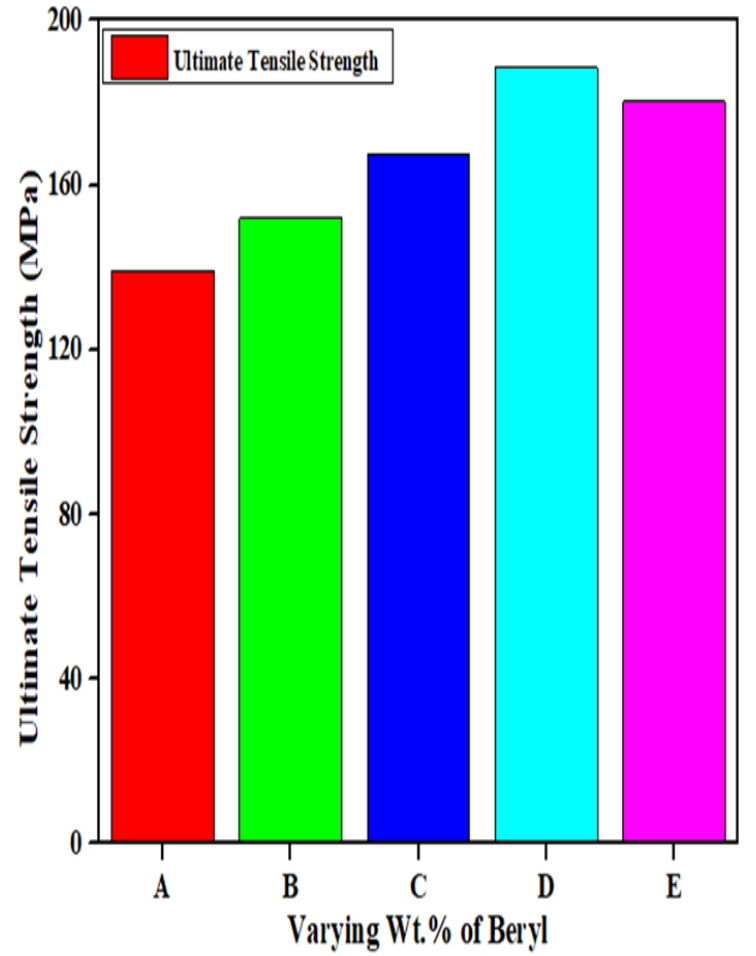

Figure 7. Ultimate tensile strength for different test samples
3.5 Yield Strength:

Table 6. Yield Strength results

\begin{tabular}{|c|c|c|}
\hline Sample & Sample Designation & $\begin{array}{l}\text { Yield Strength, } \\
\text { MDo. }\end{array}$ \\
\hline A & Al7075 & 113.773 \\
\hline $\mathrm{B}$ & Al7075 + 2wt.\% Beryl & 129.485 \\
\hline $\mathrm{C}$ & Al7075 + 4wt.\% Beryl & 144.068 \\
\hline $\mathrm{D}$ & Al7075 + 6wt.\% Beryl & 165.705 \\
\hline $\mathrm{E}$ & Al7075 + 8wt.\% Beryl & 158.601 \\
\hline
\end{tabular}

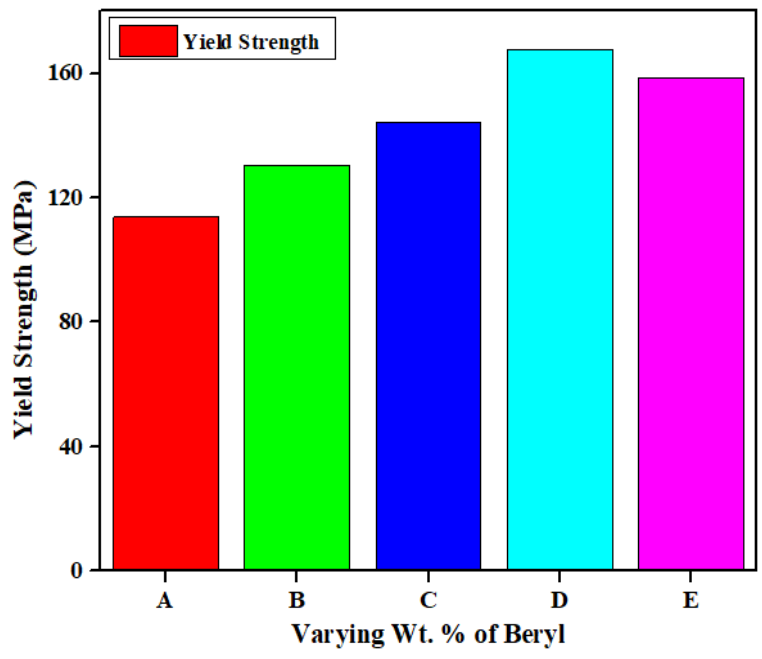

Figure 7. Yield Strength for different test samples

The yield strength of A17075-Beryl MMC increases with an increasing weight percentage of Beryl. The maximum yield strength is achieved for 6wt.\% of Beryl (Sample D). This is because of Beryl particles act as barriers to the dislocations when the external load applied. Further incorporation of brittle and hard ceramic particles in a ductile matrix [24]. The hybrid composites having $6 \mathrm{wt} . \%$ of Beryl particles showed enhancement of $45.64 \%$ as compared to Al7075 matrix material. The bonding, closer packing and smaller inter-particle spacing of reinforcement into the Al 7075 matrix alloy lead to an increase in strength.

\subsection{Hardness}

The results Brinell hardness number test on the hybrid cast specimens are tabulated in Table 7 .

Table 7. Brinell hardness test results

\begin{tabular}{|l|l|l|}
\hline Sample & Sample Designation & BHN \\
\hline A & Al7075 & 84.8 \\
\hline B & Al7075 + 2wt.\% Beryl & 91.2 \\
\hline C & Al7075 + 4wt.\% Beryl & 96.1 \\
\hline D & Al7075 + 6wt.\% Beryl & 105.8 \\
\hline E & Al7075 + 8wt.\% Beryl & 108.3 \\
\hline
\end{tabular}

The relationship between Brinell hardness number of the fabricated composites with different weight fractions of Beryl particles are shown in Figure 8 . 


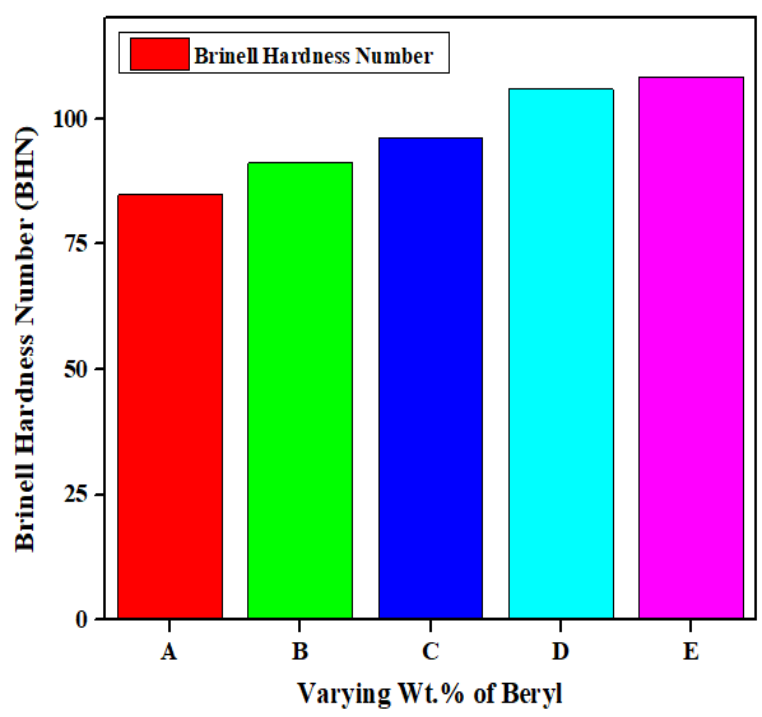

Figure 8. Brinell hardness number variation for different test samples

It is inferred from the test results that, the hardness of Al7075-Beryl MMC increases with an increasing weight percentage of Beryl. The composites attain peak hardness on the addition of 8wt. \% of Beryl particles (sample E). The composites having 6wt. \% of Beryl particles showed enhancement of $\mathbf{2 7 . 7 1 \%}$ as compared to Al7075 matrix material. This occurs due to increases in the surface area of the matrix and the reduced grain size and Beryl particles are harder than Al7075. The presence of hard Beryl particles constraint to localized deformation during indentation[18].

\subsection{Fractography:}

Fractography was used to investigate the failure mechanisms of the materials. Figure 9 depicts the fractographs of fracture surfaces of as-cast tensile samples. Ductile fracture (Shallow Dimples) was noticed in Al 7075 base metal. SEM fractography study revealed that not fully brittle in appearance for the composites. It's a combination of ductile and brittle modes for the Beryl reinforced composites. Also it is observed that as Beryl content increased, the dimples formation decreased and hence ductility decreases. The higher percentage of Beryl leads to brittle fracture and an increase in strength.
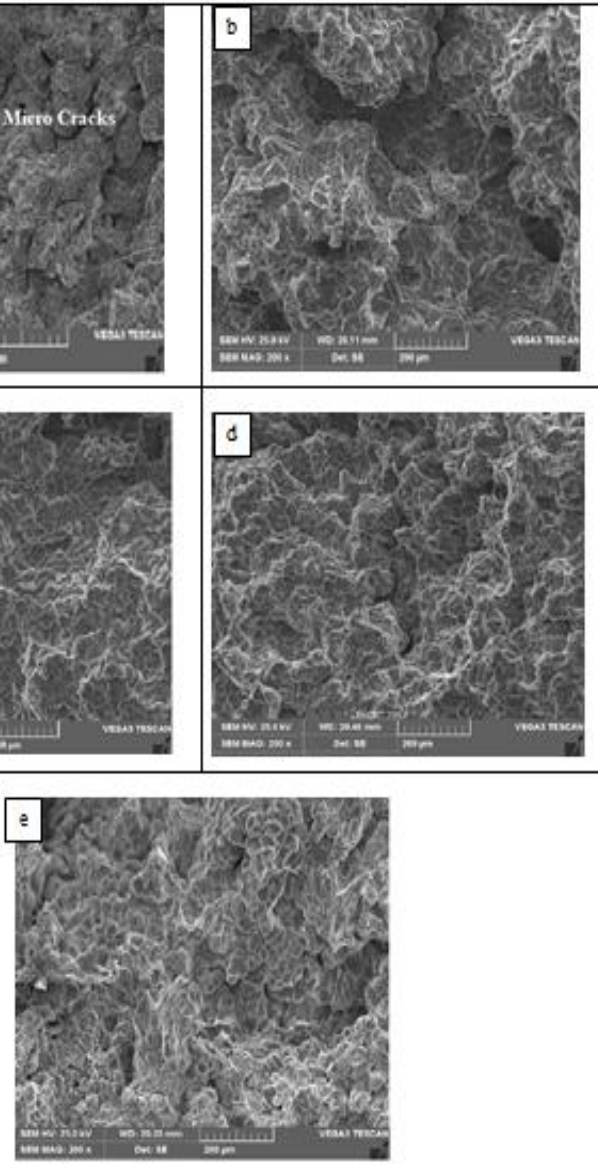

Figure 9: Tensile fracture surfaces of as-cast (a) Al7075 (b)Al7075-2wt\%Be- (c) Al7075-4wt\%Be (d) Al7075-6wt\% Be (e) Al7075-8wt\% Be

\section{CONCLUSIONS:}

1. Stir casting techniques was successfully adopted to synthesis the A17075 and A17075-Beryl composites.

2. The mechanical (Tensile strength test and hardness) properties have been investigated for both the Al7075 and Al7075-Beryl MMC.

3. The SEM analysis showed the homogeneous distributions of Beryl particles into Al7075 alloy.

4. The ultimate tensile strength of A17075-Beryl composites shows a peak strength of $188.433 \mathrm{MPa}$ at 6 wt.\% of particulate showing enhancement of $\mathbf{3 5 . 3 8 \%}$ when compared to Al7075 matrix

5. The hardness of A17075-Beryl composites demonstrations an extreme hardness of 108.3 BHN at 8 wt.\% of Be particulate showing enhancement of $\mathbf{2 7 . 7 1 \%}$ when compared to Al7075 alloy.

6. The XRD analysis has given the crystal structure and composition of Beryl particulates.

\section{ACKNOWLEDGMENTS:}

One of the authors (Mr. Shanawaz Patil) expresses heartful thanks to the Guide Dr.Mohamed Haneef, Dr. L H Manjunatha and Dr.Raju B S for their support and encouragement in carrying out this work.

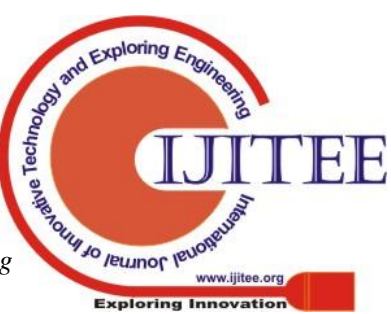




\section{REFERENCES}

1. Sambit KumarMohapatra, Kalipada Maity, "Synthesis and characterization of hot extruded aluminum-based MMC developed by powder metallurgy route:, International Journal of Mechanical and Materials Engineering, 2017, 12:2,2017, pp.-1-9

2. Sajjadi, S. A., Ezatpour, H. R., \& Beygi, H. (2011). Microstructure and mechanical properties of $\mathrm{Al}-\mathrm{Al} 2 \mathrm{O}$ 3 micro and nano composites fabricated by stir casting. Materials Science \& Engineering A, 528(29-30), 87658771. https://doi.org/10.1016/j.msea.2011.08.052

3. Sajjadi, S. A., Ezatpour, H. R., \& Parizi, M. T. (2012). Comparison of microstructure and mechanical properties of A356 aluminum alloy / Al 2 O 3 composites fabricated by stir and compo-casting processes. Materials and Design, 34 ,

$106-111$. https://doi.org/10.1016/j.matdes.2011.07.037

4. Soltani, S., Khosroshahi, R. A., Mousavian, R. T., \& Jiang, Z. (2015). Stir casting process for manufacture of $\mathrm{Al}$ - $\mathrm{SiC}$ composites. Rare Metals. https://doi.org/10.1007/s12598-015-0565-7

5. Shanmughasundaram, P., \& Ramanathan, S. (2011). Some Studies on Aluminium - Fly Ash Composites Fabricated by Two Step Stir Casting Method, (November 2014).Amirkhanlou, S., \& Niroumand, B. (2010). Synthesis and characterization of $356-\mathrm{SiC}$ p composites by stir casting and compocasting methods, 20, 788-793.

6. Balaji, V., Sateesh, N., \& Hussain, M. M. (2015). Manufacture of Aluminium Metal Matrix Composite ( A17075-SiC ) by Stir Casting Technique. Materials Today: Proceedings, 2(4-5), 3403-3408. https://doi.org/10.1016/j.matpr.2015.07.315

7. Baradeswaran, A., \& Perumal, A. E. (2013). Composites : Part B Influence of B $4 \mathrm{C}$ on the tribological and mechanical properties of $\mathrm{Al} 7075$ - B 4 C composites. COMPOSITES PART B, 54, 146-152. https://doi.org/10.1016/j.compositesb.2013.05.012

8. Bhushan, R. K., Kumar, S., \& Das, S. (2010). Effect of machining parameters on surface roughness and tool wear for $7075 \mathrm{Al}$ alloy $\mathrm{SiC}$ composite, 459-469. https://doi.org/10.1007/s00170-010-2529-2

9. Kumar, R., \& Dhiman, S. (2013). A study of sliding wear behaviors of Al-7075 alloy and Al-7075 hybrid composite by response surface methodology analysis. Materials \& Design, 50, 351-359.

10. Kalkanli, A., \& Yilmaz, S. (2008). Synthesis and characterization of aluminum alloy 7075 reinforced with silicon carbide particulates. Materials \& Design, 29(4), 775-780.

11. Reza, H., Abolkarim, S., Haddad, M., \& Huang, Y. (2014). Investigation of microstructure and mechanical properties of Al6061-nanocomposite fabricated by stir casting. Journal Of Materials \& Design, 55, 921-928. https://doi.org/10.1016/j.matdes.2013.10.060

12. Rahman, H. et al., Characterization of silicon carbide reinforced aluminum matrix composites. Procedia Engineering, 90, 103-109. https://doi.org/10.1016/j.proeng.2014.11.821

13. L. Yuan, J. Han, J. Liu, and Z. Jiang, Mechanical properties and tribological behavior of aluminum matrix composites reinforced with in-situ AlB2 particles, Tribology International, 98, (2016) 41-47.

14. A. K. Bodukuri, K. Eswaraiah, K. Rajendar, and V. Sampath, Fabrication of $\mathrm{Al}-\mathrm{SiC}-\mathrm{B} 4 \mathrm{C}$ metal matrix composite by powder metallurgy technique and evaluating mechanical properties, Perspectives in Science, 8, (2016) 428-431.

15. S. Zhang and F. Wang, Comparison of friction and wear performances of brake material dry sliding against two aluminum matrix composites reinforced with different
SiC particles, Journal of Materials Processing Technology, 182, (2007) 122-127.

16. A. Canakci, T. Varol, S. Ozsahin, and S. Ozkaya, Artificial Neural Network Approach to Predict the Abrasive Wear of AA2024-B4C Composites, Universal Journal of Materials Science, 2, (2014) 111-118.

17. E. E. Zaki, Z. H. Ismail, J. A. Daoud, and H. F. Aly, Extraction equilibrium of beryllium and aluminum and recovery of beryllium from Egyptian beryl solution using CYANEX 921, Hydrometallurgy, 80, (2005) 221-231.

18. K.R. Suresh, H.B. Niranjan, P.Martin Jabraj and M.P Chowdaiah, "Tensile and Wear Properties of Aluminum Composites, Wear, Vol. 225, No. 1-6, 2003, pp. 638-642. DOI: 10.1016/S0043-1648 (03) 00292-8

19. Hosur Nanjireddy Reddappa, Kitakanur Ramareddy Suresh, Hollakere Basavaraj Niranjan, Kestur Gundappa Satyanarayana et al., " Studies on mechanical and wear properties of Al6061/Beryl Composites," Journal of minerals and materials Characterization and Engineering, 2012, 11, 704--708 